\title{
Goji (Lycium barbarum and L. chinense): Phytochemistry, Pharmacology and Safety in the Perspective of Traditional Uses and Recent Popularity
}

Author

Affiliation
Olivier Potterat

Division of Pharmaceutical Biology, University of Basel, Basel, Switzerland

Key words
Goji
wolfberry
Lycium barbarum
Lycium chinense
Solanaceae
Novel Food

received June 25, 2009

revised August 14, 2009

accepted Sept. 21, 2009

Bibliography

DOI http://dx.doi.org/

10.1055/s-0029-1186218

Published online October 20,

2009

Planta Med 2010; 76: 7-19

(c) Georg Thieme Verlag KG

Stuttgart . New York.

ISSN 0032-0943

Correspondence

\section{PD Dr. O. Potterat}

Department of Pharmaceutical

Sciences

Division of Pharmaceutical

Biology

University of Basel

Klingelbergstrasse 50

4056 Basel

Switzerland

Phone: + 41612671534

Fax: +41612671474

olivier.potterat@unibas.ch

\section{Abstract}

$\nabla$

Since the beginning of this century, Goji berries and juice are being sold as health food products in western countries and praised in advertisements and in the media for well-being and as an anti-aging remedy. The popularity of Goji products has rapidly grown over the last years thanks to efficient marketing strategies. Goji is a relatively new name given to Lycium barbarum and L. chinense, two close species with a long tradition of use as medicinal and food plants in East Asia, in particular in China. While only L. barbarum is officinal, the fruit (fructus Lycii) and the root bark (cortex Lycii radicis) of both species are used in the folk medicine. We review here the constituents, pharmacology, safety, and uses of L. barbarum and L.chinense with consideration to the different parts of the plant. Investigations of the fruit have focused on proteoglycans, known as "Lycium

\section{Introduction}

\section{$\nabla$}

Since the beginning of the 21th century, wolfberries (Lycium barbarum, Solanaceae) a traditional food and medicine in East Asia have become increasingly popular in Europe and North America. Numerous products are commercialized under the relatively new name Goji on the health food market. Goji products are sold in particular via the Internet and praised for well-being and longevity. Meanwhile Goji is also found in conventional food products such as yoghurts.

There are in fact two closely related species, L. barbarum and L.chinense, which both have a long tradition as food and medicinal plants in China and other Asian countries. The berries of both species are a very popular ingredient in Chinese cuisine. They are consumed in soups, as porridge with rice and added to numerous meat and vegetable dishes. The fruits which are harvested from barbarum polysaccharides", which showed antioxidative properties and some interesting pharmacological activities in the context of age related diseases such as atherosclerosis and diabetes. As to the root bark, several compounds have demonstrated a hepatoprotective action as well as inhibitory effects on the rennin/angiotensin system which may support the traditional use for the treatment of hypertension. While there are no signs of toxicity of this plant, two cases of possible interaction with warfarin point to a potential risk of drug interaction. In view of the available pharmacological data and the long tradition of use in the traditional Chinese medicine, L.barbarum and $L$. chinense certainly deserve further investigation. However, clinical evidences and rigorous procedures for quality control are indispensable before any recommendation of use can be made for Goji products.

August to October are usually dried, but they may also be consumed fresh, like the young leaves which are a valued vegetable. Goji products sold outside Asia contain, according to the suppliers, exclusively $L$. barbarum berries. However, distinction of wolfberries from different species and varieties is difficult so that substitution or adulteration in commercial products cannot be excluded. Beside its alimentary use, Goji plays an important role in the Chinese traditional medicine. The medicinal tradition not only uses the berries (fructus Lycii) as a renowned Yin strengthening agent but also the root bark (cortex Lycii radicis) as a cooling agent.

Despite the importance of Goji in the traditional Chinese medicine and its new popularity in the Novel Food market, there are no comprehensive reviews on its constituents, pharmacology, safety and uses until now. We published recently a short review focusing on the fruit of $L$. barbarum and its 
use in Novel Food products [1]. We have now extended our literature survey to include $L$. chinense and the other plant parts of both species. In addition to the comprehensive review on the chemistry, pharmacology and safety of the plant, the uses in the traditional Chinese medicine are summarized. Finally, the recent emergence of Goji products on the Novel Food market is addressed and legal issues associated with these products are briefly discussed.

\section{Botanical Aspects}

Lycium barbarum L. (syn L. halimifolium Miller) (Chinese: Gouqi or Ningxiagouqi) and L.chinense Miller (Gouqi) are two closely related species with congruent uses as food and medicinal plants in East Asia. In addition there are some varieties and related species such as L. barbarum var. aurantiocarpum (Huangguogouqi), L. chinense var. potaninii (Beifanggouqi), L. ruthenicum (Heiguogouki) and L.truncatum (Jieegouki) which can be found on the market as low cost adulterants [2]. Traditional English vernacular names include boxthorn, wolfberry, Chinese wolfberry, or matrimony wine [3]. The plant is known as kuko in Japan and gugija in Korea. Since the beginning of the century, the plant is commonly called Goji, an appellation derived from the Chinese name gouqi. L. barbarum L. is a deciduous shrub one to three meters high while L.chinense is somewhat smaller. The leaves are lanceolate to ovate. The oblong, orange to dark red berries measure up to $2 \mathrm{~cm}$ and possess a bitter to sweet taste. The fruits of Lycium species possess a highly similar anatomy and tissue structure. Differentiation based on morphological and histological analyses is very delicate. Confident distinction requires molecular techniques such as RAPD (random amplified polymorphic DNA) analyses $[2,4]$.

The original habitat of L. barbarum is not definitively established but is probably to be found in the Mediterranean Basin [5]. Meanwhile, the plant is widely distributed in warm regions of the world, in particular in the Mediterranean area, Southwest and Central Asia. It is also cultivated in North America and Australia as hedge plant [3]. L. chinense is mainly distributed in East Asia and grown in particular in South China, Korea, and Japan [6]. The majority of commercially produced wolfberries come from plantations of L. barbarum in the Ningxia Hui Region in northcentral China and the Xinjiang Uyghur Region in western China. In addition, L.barbarum is grown also in sheltered valleys of Mongolia.

\section{Traditional Medicinal Use of Wolfberry}

$\nabla$

The traditional Chinese medicine makes use of both the root bark (Digupi) and the fruit (Gouqizi). The utilization of the leaves and the seeds is also mentioned in a few medicinal books [7]. Besides China, Goji is part of the medicinal tradition in other Asian countries including, Vietnam [8], Korea, and Japan. While only L. barbarum is officinal in the Pharmacopoeia of the People's Republic of China [9], both species, L. barbarum and L. chinense, have been used for more than 2000 years in the traditional Chinese Medicine with early records tracing back to the Tang Dynasty (1000$1400 \mathrm{AD}$ ) [10]. There are some discrepancies in the medical books with regard to the species to be used. Some treaties include both species as a source of the drug, while others recommend ei- ther L. chinense or L. barbarum. Indications however are essentially congruent.

The berries are eaten raw, drunk as a juice, wine or tea. They can also be processed to tinctures, powders, and tablets. The recommend dosage of dried berries varies between 5 and $12 \mathrm{~g}[11,12]$. Goji berries are used in traditional Chinese medicine as a mild Yin tonic, enriching Yin in liver, kidneys and moistening lung Yin. Indications derive from the Yin nourishing effect. They include blurry vision and diminished visual acuity, infertility, abdominal pain, dry cough, fatigue, and headache [11-15]. The berries are also praised in the folk medicine to increase longevity [16] and against prematurely gray hair [13]. Medicinal beverages and dietary soups are available at the interface between food and medicine.

The root bark is used as a cooling agent to "clear heat" and lower consumptive fever due to Yin deficiency. It is usually taken as a decoction with a dosage varying between 6 and $15 \mathrm{~g}$. The drug is, in particular, prescribed for night sweating, "steaming bone sensation" [13] and chronic low-grade fever. A decoction of the root bark is effective for treating cough and recommended against hemoptysis and hematuria [13]. Finally it is indicated for the treatment of diabetes mellitus and hypertension $[11,14,15$, 17].

\section{Constituents of $L$. barbarum and $L$. chinense $\nabla$}

There have been several investigations of the constituents of wolfberry, and the different organs of the plant have been studied. Investigations on the fruit have been performed mostly with $L$. barbarum, the officinal species considered to be of higher quality. On the other hand, for reasons which are not fully clear, studies on other organs, in particular the roots and the leaves, have focused on L.chinense. The constituents of wolfberry are presented below. The data have been organized by plant parts.

\section{Fruits}

Polysaccharides represent quantitatively the most important group of substances in the fruit of $L$. barbarum. Quantitative data in the literature diverge considerably, but a yield of $23 \%$ based on the dried fruit which was obtained after optimization of the extraction conditions [18] can be considered as a reliable value. The polysaccharide fraction, referred to as Lycium barbarum polysaccharides or LBP consists of a complex mixture of highly branched and only partly characterized polysaccharides and proteoglycans. An overview of the fractions which have been purified in homogenous form is presented in $\bullet$ Table 1. The glycosidic part accounts, in most cases, for about $90-95 \%$ of the mass and consists of arabinose, glucose, galactose, mannose, rhamnose, xylose, and/or galacturonic acid [19-28]. More recently, the polysaccharides of L. barbarum have been also analyzed by preparative high performance size exclusion chromatography (HPSEC). After protein hydrolysis, two major fractions were obtained with a molecular weight of 79250 and 24470 amu, respectively [29]. The monosaccharidic composition of the whole polysaccharidic fraction has been determined by GC after hydrolysis. There are however some discrepancies in the literature, in particular with regard to the presence of fucose and mannose as well as the content of glucose. Thus the composition was found to be Rha, Ara, Xyl, Man, Glc, and Gal (molar ratio of $0.3: 2.7: 0.3: 0.2: 2.7: 0.9$ ) [29] or Rha, Ara, Xyl, Fuc, Glc, Gal (1:2.14:1.07:2.29:3.59: 10.06) [30], respectively, in two similar recent studies. 
Table 1 Homogenous polysaccharidic constituents purified from the fruit of L. barbarum and L. chinense.

\begin{tabular}{|c|c|c|c|c|}
\hline Glycoconjugate & MW & Carbohydrate content & Monosaccharides (molar ratio or \%) & Reference \\
\hline \multicolumn{5}{|l|}{ L. barbarum } \\
\hline LbGp2 & 68200 & 90.7 & Ara, Gal (4:5) & [19] \\
\hline LbGp3 & 92500 & 93.6 & Ara, Gal (1:1) & {$[20,21]$} \\
\hline LbGp4 & 214800 & 85.6 & Ara, Gal, Rha, Glc (1.5: $2.5: 0.43: 0.23)$ & {$[20,22]$} \\
\hline LbGp5 & 23700 & 8.6 & $\begin{array}{l}\text { Rha, Ara, Xyl, Gal, Man, Glc } \\
(0.33: 0.52: 0.42: 0.94: 0.85: 1)\end{array}$ & {$[20]$} \\
\hline LbGp5B & 23700 & & Rha, Ara, Glc, Gal, (0.1:1:1.2:0.3), Galu (0.9\%) & [23] \\
\hline LBP3p & 157000 & 92.4 & $\begin{array}{l}\text { Gal, Glc, Rha, Ara, Man, Xyl } \\
(1: 2.12: 1.25: 1.10: 1.95: 1.76)\end{array}$ & [24] \\
\hline $\mathrm{LBPC}_{2}$ & 12000 & 92.8 & Xyl, Rha, Man $(8.8: 2.3: 1)$ & {$[25,26]$} \\
\hline $\mathrm{LBPC}_{4}$ & 10000 & 95 & Gle & {$[25,26]$} \\
\hline LBPA1 & 18000 & & heteroglycan & {$[26]$} \\
\hline LBPA3 & 66000 & & heteroglycan & [26] \\
\hline LBP1a-1 & 11500 & & Glc & [28] \\
\hline LBP1a-2 & 9400 & & Glc & [28] \\
\hline LBP3a-1 & 10300 & & GalA & [28] \\
\hline LBP3a-2 & 8200 & & GalA & [28] \\
\hline LBPF1 & ca 150000 & $48.2^{*}$ & & [27] \\
\hline LBPF2 & ca 150000 & $30.5^{*}$ & & [27] \\
\hline LBPF3 & ca 150000 & $34.5^{*}$ & & [27] \\
\hline LBPF4 & ca 150000 & $20.3^{*}$ & & [27] \\
\hline LBPF5 & 290000 & $23.5^{*}$ & & [27] \\
\hline \multicolumn{5}{|l|}{ L. chinense } \\
\hline Cp-1-A & 10000 & 87.8 & Ara, Xyl (1: 1) & [48] \\
\hline Cp-1-B & 11000 & 89.4 & Ara & [48] \\
\hline Cp-1-C & 42000 & 92.4 & Ara, Gal (3: 1) & [48] \\
\hline Cp-1-D & 23000 & 90.7 & Ara, Gal (1: 1) & [48] \\
\hline Cp-2-A & 89000 & 88.3 & $\begin{array}{l}\text { Ara (50.6\%), Gal (22.8\%), Man (8.4\%), Rha } \\
(5.9 \%) \text {, Glc (5.6\%) }\end{array}$ & [49] \\
\hline Cp-2-B & 71000 & 87.5 & Ara (45.5\%), Gal (47.4\%) & [49] \\
\hline Hp-2-A & 8000 & 87.9 & $\operatorname{Ara}(70.6 \%)$, Gal (13.5\%) & [49] \\
\hline Hp-2-B & 11000 & 89.9 & $\operatorname{Ara}(84.2 \%)$, Gal (10.7\%) & [49] \\
\hline $\mathrm{Hp}-2-\mathrm{C}$ & 120000 & 90.7 & Ara (49.5\%), Gal (40.8\%), Fuc (5.9\%) & [49] \\
\hline Hp-O-A & 23000 & & Ara & [50] \\
\hline
\end{tabular}

* The carbohydrate content has been determined by the phenol-sulfuric acid assay. The content is much higher when it is put in relation to the protein content

A second major group of metabolites are the carotenoids, the content of which increases during the ripening process [31]. Zeaxanthin dipalmitate (1) is the predominant constituent [32] ( Fig. 1) representing $56 \%$ of the total carotenoids in the fruit [33]. $\beta$-Cryptoxanthin palmitate (2), zeaxanthin monopalmitate (3), small amount of free zeaxanthin (4) and $\beta$-carotene (5) are also present [34]. As to the seeds, they contain zeaxanthin (83\%), $\beta$-cryptoxanthin (6) (7\%), $\beta$-carotene $(0.9 \%)$, mutatoxanthin (7) $(1.4 \%)$, as well as some minor carotenoids which have not been definitively identified [35]. The fruits further contain vitamins, in particular riboflavin, thiamin and ascorbic acid, together with a glucosylated precursor $(8)$ of the latter $[36,37]$ ( Fig. 2). The content of vitamin C of $42 \mathrm{mg} / 100 \mathrm{~g}$ is comparable to that of fresh lemon fruits. Flavonoids are another important class of compounds. The aglycones myricetin, quercetin, and kaempferol have been identified after hydrolysis [38]. The essential oil and fatty acids of L. barbarum have been analyzed by GC-MS, and hexadecanoic acid, linoleic acid, $\beta$-elemene, myristic acid and ethylhexadecanoate have been identified as the main constituents [39]. Among the nonpolar constituents, a series of glycerogalactolipids (9-23) have been recently isolated [40] ( Fig. 2). The fruit further contains $1-2.7 \%$ free amino acids with proline as the major constituent. The non-proteinogenic amino acids taurine and $\gamma$-aminobutyric acid, as well as betaine (trimethylglycine) are also contained in the fruit $[41,42]$. Finally, some miscellaneous compounds have been isolated including $\beta$-sitosterol and its glucoside daucosterol, scopoletin, p-coumaric acid [43], the dopamine derivative lyciumide A (24) (○ Fig. 3) [44], and L-monomenthyl succinate [45].

There have been some controversies about the atropine content of the fruits. In 1989 , a content of $0.95 \%$ of atropine was reported for a fruit sample collected in India [46]. This finding appears highly doubtful and is in obvious contradiction with the widespread consumption of the fruits and lacking reports of apparent toxicity. In this context, a systematic investigation of Goji berries from various provenances which has been recently performed with HPLC-MS [47] revealed only traces of atropine, maximally $19 \mathrm{ppb}(\mathrm{w} / \mathrm{w})$, in the analyzed samples.

The composition of the fruit of $L$. chinense appears similar. As in L. barbarum, polysaccharides, carotenoids and flavonoids are the typical metabolites. With regard to the polysaccharidic fraction, an arabinoxylan (Cp-1-A), two arabinans (Cp-1-B and Hp-0-A) and a series arabinogalactan proteoglycans were purified ( $\odot$ Table 1) [48-50]. Rutin is the main flavonoid and is accompanied by small amounts of hyperoside, quercetin, and morin [6]. The carotenoid composition is similar to that found in L. barbarum. Zeaxanthin dipalmitate (1) is here also the dominant constituent making $49 \%$ of the carotenoid fraction [33]. The fruit further contains zeaxanthin (4) [51] and $\beta$-carotene (5) [52]. In addition, two cerebrosides $(\mathbf{2 5}, \mathbf{2 6})(\bullet$ Fig. $\mathbf{2})[53]$ and three pyrrole derivatives 


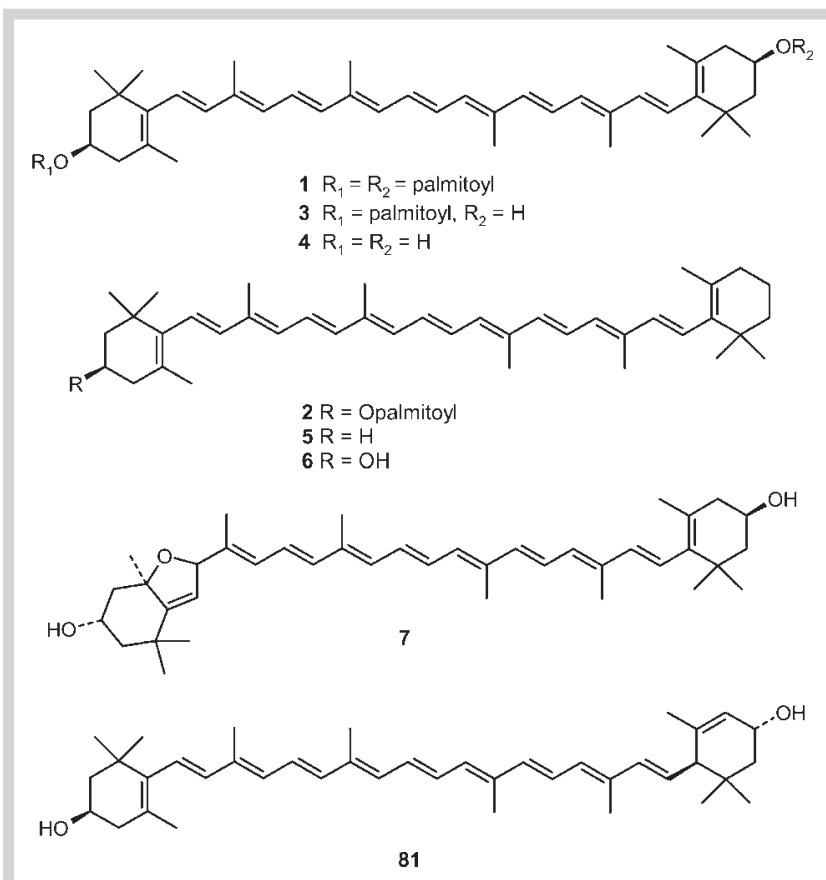

Fig. 1 Carotenoids from the fruits and the leaves.

(27-29) [54] with hepatoprotective properties have been isolated (- Fig. 3). The identification of tocopherols, phenolic acids including gallic, caffeic, and protocatechuic acids, chlorogenic and neochlorogenic acids has been reported [52]. The sterols contained in the seeds have been analyzed as part of investigations on the sterols contained in the seeds of various Solanaceae plants: cycloartenol, cycloartanol, and 24-methylenecycloartanol [55], gramisterol and citrostadienol [56], and 24-etylcholesterol, 24-methylcholesta-5,24-dienol, and 28-isofucosterol [57] have been found to be the major constituents of the 4,4-dimethyl, 4methyl, 4-desmethyl sterol fractions, respectively. A mixture of 6 '-O-palmitoyl- and 6'-O-stearoyl- $\beta$-sitosterol-3-O-glucoside has been obtained together with two glycerogalactolipids ( $\mathbf{3 0}$, 31) [58] ( Fig. 2). In an investigation of the volatile constituents, megastigmatrienone, $\beta$-ionone and 3-hydroxy- $\beta$-ionone were found to be the main ketones. Hydrocarbons include $\beta$-elemene and $\delta$-cadinene. Phenethyl alcohol and benzyl alcohol were accompanied by smaller amounts of linalool and terpinen-4-ol [59]. The sesquiterpenes solavetivone (32) and 1,2-dehydro- $\alpha$ cyperone (33) were isolated from the essential oil [60] (๑ Fig. 3). Finally large amounts of methyl linoleate together with further esters of C16 and C18 fatty acids were detected [59]. Recently a study on aroma-active compounds combining GC-MS and GC-olfactometry showed that 1-octen-3-ol, 3-hydroxy-2-butanone, acetic acid, hexanal and (E)-2-heptenal were the most contributing odor components [61].

\section{Roots}

Investigations on the underground parts have focused on $L$. chinense. A great variety of secondary metabolites have been isolated from the roots or the root bark. Of particular interest is a group of cyclic peptides, licyumins A-D (34-37) [62-64] (๑ Fig. 4). The authors also isolated in the course of their studies an indole glycoside (38) derived from tryptophan [62] (๑ Fig. 3). Further nitrogenous compounds include aurantiamide acetate
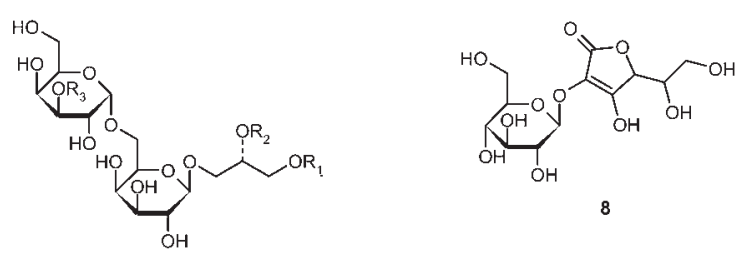

$9 R_{1}=$ palmitoyl, $R_{2}=R_{3}=$ linolenoyl $10 R_{1}=$ palmitoyl, $R_{2}=$ linolenoyl $R_{3}=$ linoleoyl

$11 R_{1}=R_{3}=$ palmitoyl, $R_{2}=$ linolenoyl

$12 R_{1}=R_{3}=$ palmitoyl, $R_{2}=$ linoleoyl

$13 R_{1}=R_{2}=R_{3}=$ palmitoyl

$14 \mathrm{R}_{1}=\mathrm{R}_{2}=$ palmitoyl, $\mathrm{R}_{3}=\mathrm{H}$

$15 R_{1}=R_{2}=$ linolenoyl, $R_{3}=H$

$16 R_{1}=$ linolenoyl, $R_{2}=$ linoleoyl,$R_{3}=H$

$17 R_{1}=$ palmitoyl, $R_{2}=$ linolenoyl, $R_{3}=H$

$18 R_{1}=$ palmitoyl, $R_{2}=$ linoleoyl, $R_{3}=H$

$19 R_{1}=$ palmitoyl, $R_{2}=$ oleoyl, $R_{3}=H$

$20 R_{1}=$ stearoyl, $R_{2}=$ linoleoyl, $R_{3}=H$

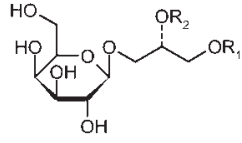

$21 R_{1}=$ palmitoy $\mid, R_{2}=$ linolenoyl

$22 \mathrm{R}_{1}=$ palmitoy $\mid, \mathrm{R}_{2}=$ linoleoyl

$23 \mathrm{R}_{1}=$ palmitoyl, $\mathrm{R}_{2}=$ oleoyl

$30 R_{1}=R_{2}=$ linolenoy

$31 R_{1}=$ linoleoyl, $R_{2}=$ linolenoy

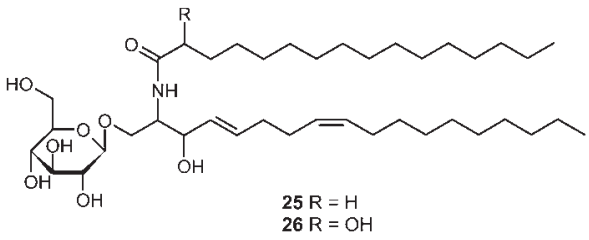

Fig. 2 Vitamin C precursor and glycolipids from the fruits.

(39) [65], lyciumamide (40) [66], and a series of tyramine derivatives (41-44) $[67,68]$. The roots contain alkaloids, such as the spermine alkaloids kukoamines A (45) [69] and B (46) [70] ( Fig. 3). A series of calystegenines and $\mathrm{N}$-metylcalystegines (47-61), among these some compounds with $\beta$-glucosidase and/ or $\alpha$-galactosidase inhibitory activity, as well as two polydroxylated piperidine alkaloids, fagomine (62) and 6-deoxyfagomine (63) were also purified [71] ( Fig.5). With regard to polyphenolic compounds, the roots contain the flavonoids apigenin, acacetin, luteolin, kaempferol, and quercetin [72], as well as the flavone glycoside linarin [73]. The coumarin scopoletin, and its glycosides scopolin and fabiatrin (7-O- $\beta$-xylopyranosyl- $(1 \rightarrow 6)-\beta$ glucopyranosylscopoletin) have been isolated [74]. The lignan (+)-lyoniresinol-30- $\beta$-D-glucopyranoside (64) has been obtained from the root bark $[67,75]$ ( $\bullet$ Fig. 6). A series of anthraquinones, including physcion, emodin, 1,3,6-trihydroxy-2-methylanthraquinone, and the glycoside 65 have been reported $[74,76]$. Phenolic acids and glycosides, such as p-coumaric and vanillic acids, syringic acid-O-glucoside and digupigan A (66) have been reported [72,73]. Terpenoids include $5 \alpha$-stigmastane-3,6-dione [77], the diterpene sugiol (67) [77], the steroidal glycoside 68 and a monoterpene glycoside (69) [62]. The fatty acids $\alpha$-dimorphecolic acid (= 9-hydroxy-E-10,Z-12-octadecadienoic acid) and 9-hydroxy-E-10,Z-12,Z-15 octadecatrienoic acid were isolated as ACE inhibitors [65]. Finally, the presence of vitamin C (cited in [62]) and betain [78] must be mentioned.

There are comparatively few investigations on L. barbarum roots. The cyclooctapeptides lyciumins A and B $(34,35)$ which have been isolated from $L$. chinense were also detected in the roots of L. barbarum by HPLC [62]. The roots further contain betain [79], choline [80], linoleic acid and $\beta$-sitosterol [79]. The presence of atropine in the roots was reported in the same publication in which a high concentration of this alkaloid was reported in the 
<smiles>[R9]COc1ccc(CO)n1CCCC(=O)O[R]([H])([H])[H]</smiles>

Fig. 3 Amides and miscellaneous compounds from the fruits and the roots. fruits [46]. However, this stays in contradiction with results obtained previously which excluded the occurrence of atropine and scopolamine [80] in the root bark.

\section{Leaves and flowers}

Phytochemical investigations on leaves have focused on L.chinense, and only limited information is available on the constituents of $L$. barbarum. Terpenoids are certainly the most interesting constituents of the leaves of $L$. chinense. A series of acyclic diterpene glycosides, lyciumosides I-IX (70-78) [62,81], have been isolated. Lyciumosides appear rather specific of L.chinense and have been otherwise only detected in Nicotiana attenuata [82] ( Fig. 6). Two steroids of the withanolide type, withanolides A (79) and B (80) have been purified already in the 1970s [83]. These compounds, which are typical constituents of Withania somnifera, display anti-inflammatory properties and have long been considered to be the main active principle of herba Lycii. Finally, $\beta$-sitosterol and its glucoside have been isolated [84]. Flavonoids represent a further group of important metabolites in the leaves. The aglycones apigenin, quercetin, acacetin, luteolin, and 5,7,3'-trihydroxy-6,4',5'trimethoxyflavone have been identified [85]. Glycosides include rutin, quercetin-3-O-sophoroside, quercetin-7-O-glucoside-3-0-sophoroside, kaempferol-3-O-sophoroside, kaempferol-7-O-glucoside-3-O-sophoroside, and acacetin-7-0- $\alpha$-L-rhamnopyranosyl-( $1 \rightarrow 6)-\beta$-D-glucopyranoside

[85-87]. The carotenoids lutein (81) and $\beta$-caroten (5) have been detected. Miscellaneous phenolic compounds include scopoletin [88], vanillic acid [88] and chlorogenic [81] acid. Nitrogenous compounds comprise the ubiquitous metal chelator nicotianamine (82) [89], hypoxanthine, and the nucleosides inosine, cytidine 5'-monophosphate and uridin-5'-monophosphate [90]. The free amino acid composition undergoes strong seasonal variation, but alanine, histidine and proline dominate [91]. Citric acid is the major nonvolatile organic acid in the leaves followed by oxalic acid [91]. Fructose, galactose, maltose, and sucrose were found as free sugars [91]. The volatile constituents of the leaves have been comprehensively investigated by GC-MS [91]. 45 compounds were identified, including ionol (isomer not indicated, but probably $\beta$-ionol), menthol, limonene, as well as large amounts of 3-hexadecen, 2-methylbutanal and phytol. 3-Hy- 


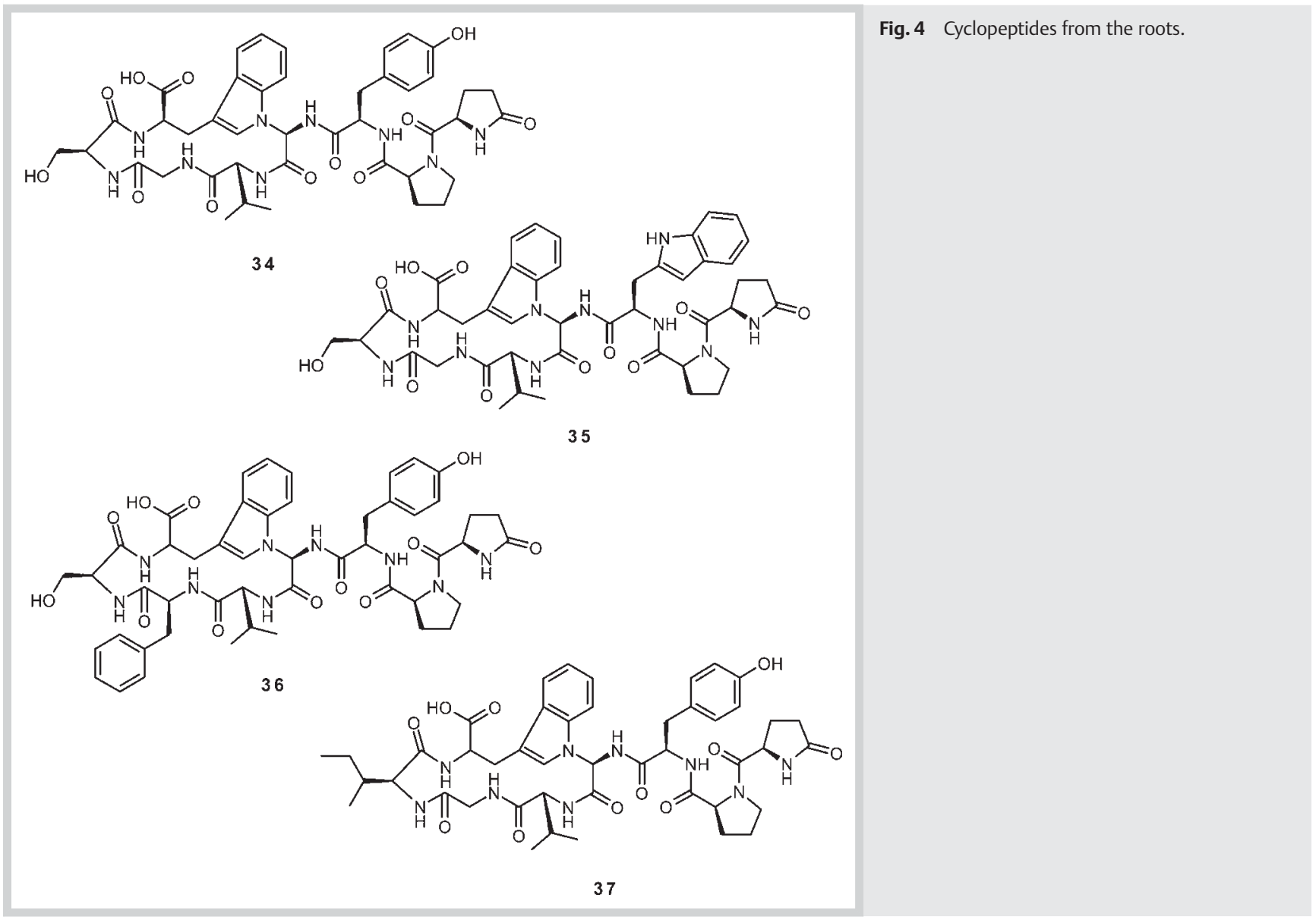

droxy-7,8-dehydro- $\beta$-ionone has been isolated [92]. Finally, the content of total tannins in the leaves has been determined to be $0.90-2.10 \%$ using the AOAC (1985) method, but structural information is not available [91].

Little is known about the constituents of the leaves of L. barbarum. The flavonoids quercetin 3-O-rutinoside-7-O-glucoside, kaempferol 3-O-rutinoside-7-0-glucoside, rutin, nicotiflorin, isoquercitrin, quercetin, and kaempferol have been isolated [93]. In addition, damascenone (83), and a glucosidic precursor thereof (84) [94], choline [80], scopoletin, vanillic acid, salicylic acid [95], and nicotinic acid [96] have been reported. Finally, diosgenin, $\beta$-sitosterol, and lanosterol have been isolated from the flowers [97].

\section{Pharmacological Studies \\ $\nabla$}

Fruits

Pharmacological investigations on L. barbarum fruit were almost exclusively from China and have been usually performed with an aqueous extract or more or less purified polysaccharide fractions. In this context, it must be critically pointed out as a preliminary remark that no data are available on the pharmacokinetics of LBP and their bioavailability is not studied. Investigations have focused on antioxidative and immunomodulatory properties in the context of age-related diseases including atherosclerosis, neurodegeneration and diabetes [98]. Antioxidant properties have been detected in various in vitro and in vivo assays. The activity has been mainly attributed to the polysaccharides (LBP)
$[99,100]$ and flavonoids [38]. For both groups of compounds, the mechanisms of action involve reducing capacity, metal ion chelation and radical scavenging activity $[38,100]$. Betain could also contribute to the antioxidant action [101]. Of particular interest is the activity of the polysaccharides, since these constituents are relatively characteristic of Goji fruit. Polysaccharides extracted from the fruit exhibited antioxidant activity in the $\beta$-carotene/linoleic acid assay as well as radical scavenging activity towards the superoxide anion and reducing capacity which were similar to those of the synthetic antioxidant BHT [99]. They also strongly inhibited the AAPH [2,2'-azobis (2-amidinopropane) dihydrochloride] induced hemolysis of erythrocytes. The glycoconjugate LbGp5B inhibits LDL oxidation in vitro [23]. LBP showed protective effects on heat induced damages in rat testes in vivo per os and $\mathrm{H}_{2} \mathrm{O}_{2}$-induced oxidative damage in mouse testicular cells in vitro [102]. In rabbits fed with $1.5 \%$ cholesterol over ten weeks, celiac injection of LBP reduced the increase of triglyceride, increased the ratio of HDL cholesterol to total cholesterol and improved oxidation markers [103]. Oral infusion of LBP decreased the levels of LDL, triglycerides and total cholesterol, while increasing the activities of antioxidant enzymes in mice fed with high-fat diet [104]. Oral administration of LBP exhibited protective effects on streptozotocin induced oxidative stress and DNA damages in diabetic rats $[105,106]$. In the same model, they markedly decreased the plasma cholesterol, fasting insulin and postprandial glucose levels. Improved insulin sensitivity was associated with increased levels of the glucose transporter 4 (GLUT4) on the surface of skeletal muscle cells [107]. Hypoglycemic and hypolipidemic effects have also been observed in allox- 

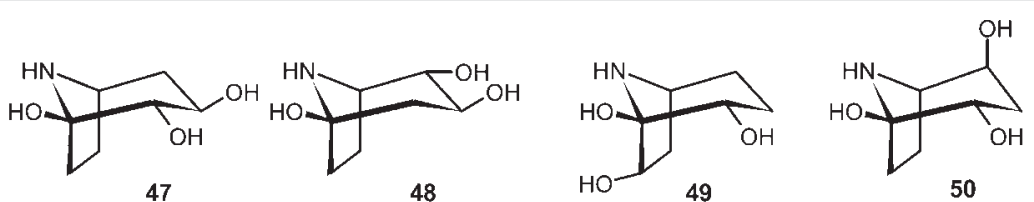

Fig. 5 Alkaloids from the roots of $L$. chinense.

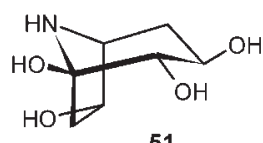

51
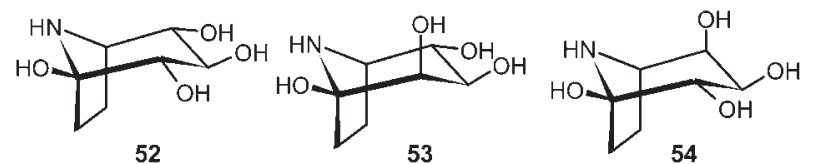

53

54
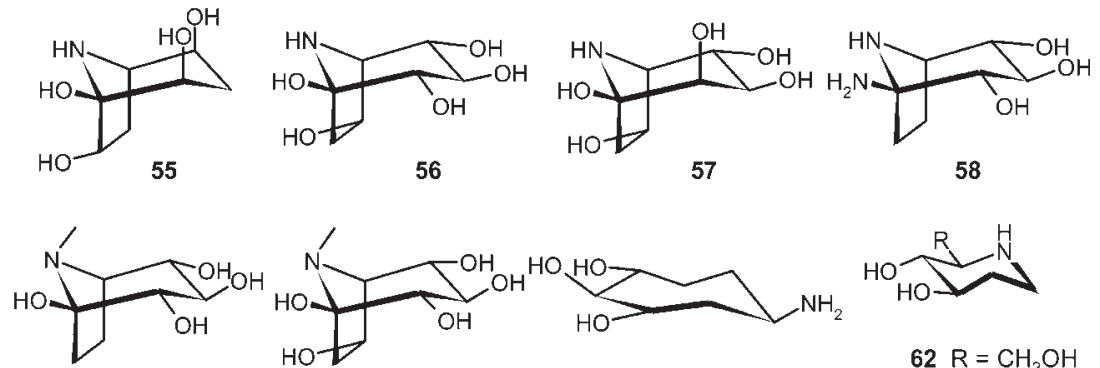

59

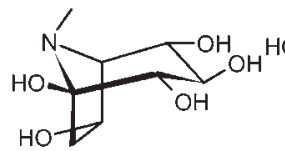

60

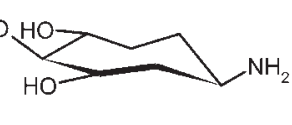

61

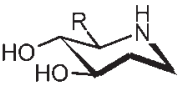

$62 \mathrm{R}=\mathrm{CH}_{2} \mathrm{OH}$ $63 \mathrm{R}=\mathrm{CH}_{3}$ an-induced diabetic/hyperlipidemic rabbits [108] treated by oral infusion of a fruit water decoction, as well as crude and purified LBP fractions.

Immunomodulatory properties have attracted much attention, also in the perspective of cancer immunotherapy. LBPs have been shown in several studies to promote splenocyte proliferation [22-24,109] in vitro. T lymphocyte proliferation was reported in vitro and in mice which received LBP, LBPF4, or LBPF5 i.p. or p.o. [27]. LBP induces dendritic cell maturation and enhances their immunogenicity. Dentritic cells activated by LBP in vitro enhance Th1 and Th2 responses both in vitro and in vivo [110]. There are evidences that LBPs act through enhanced expression of various cytokines and transcription factors. The protein polysaccharide complex LbGp4 stimulates the expression of nuclear factor $k \mathrm{~B}$ $(\mathrm{NF} k \mathrm{~B})$ and activator protein 1 (AP-1) [22]. LBP3 was shown to increase the expression of interleukin-2 (IL-2) and tumor necrosis factor- $\alpha$ (TNF- $\alpha$ ) at the mRNA and protein levels in cultures of human peripheral blood mononuclear cells [111]. The immunostimulatory activity appears to account for the antitumor properties which have been detected in mice. Thus, inhibition of the growth of S180 sarcoma tumors in mice treated p.o with LBP3p, a purified fraction from LBP3, was correlated with increased macrophage phagocytosis, spleen lymphocyte proliferation, CTL activity, and IL-2 mRNA expression [112]. In addition to immunostimulatory effects, propapoptotic properties may contribute to the antitumor properties. LBP inhibits cell proliferation with cell cycle arrest in the $S$ phase and induce apoptosis of a human hepatoma cell line in vitro [113]. Apoptosis is stimulated by a water extract in hepatocellular carcinoma cells [114]. Inhibition of proliferation of prostate cancer cells PC3 in vitro has also been reported. In the latter study, activity has been, however, quite strangely assigned mainly to scopoletin [115]. Recently, an aqueous extract was shown to inhibit the growth of the estrogen receptor positive human breast cancer cell line MCF-7, and alteration of estradiol cellular metabolism has been suggested as the mechanism [116]. Finally, hematopoietic properties should be mentioned in the context of a potential use as adjuvant in cancer therapy. In irradiation- or chemotherapy-induced myelosuppressed mice, LBP injected subcutaneously alleviated the decrease of red and white blood cells, an effect which may be due to the stimulation of PBMCs (peripheral blood mononuclear cells) to produce G-CSF (granulocyte colony stimulating factor) production [117].

Another line of interest has been on neuroprotective properties. It must, however, be noted that work in this field is almost solely from a single research group at the University of Hong Kong and the data are mainly in vitro. Pretreatment with an aqueous extract of $L$. barbarum fruits has been shown to protect rat cortical neurons against $A \beta$ induced toxicity in vitro. The underlying mechanism appears to involve inhibition of the $A \beta$-triggered $c$ Jun N-terminal kinase (JNK) signaling pathway [118]. L. barbarum extract also protects against reducing stress induced by dithiothreitol, which indicates that the neuroprotective activity is not merely due to antioxidative properties [119]. The same authors also observed reduced activity of caspases 3 and 2 and inhibition of phosphorylation of double-stranded RNA-dependent protein kinase (PKR) [120]. In one of the rare in vivo studies, neuroprotective effects have been investigated in an ocular hypertension model of glaucoma. Rats fed with an aqueous extract of L. barbarum showed a strong reduction of the retinal ganglion cell loss. The intraocular pressure was not altered by the treatment [121].

There have been fewer investigations on L. chinense fruit. The focus of the investigations has been, as for L. barbarum, on the antioxidative properties but more specifically in the context of hepatoprotection. Free radical scavenging properties of polar extracts against the DPPH radical have been correlated with the flavonoid content [6]. Work on hepatoprotection has been for the most part carried out at the Seoul University, South Korea. $\mathrm{A} \mathrm{CHCl}_{3}-\mathrm{MeOH}$ extract displayed protective activity against $\mathrm{CCl}_{4}$-induced hepatotoxicity. The activity of the hexane-soluble fraction of this extract was attributed to zeaxanthin (4) and zeaxanthin dipalmi- 


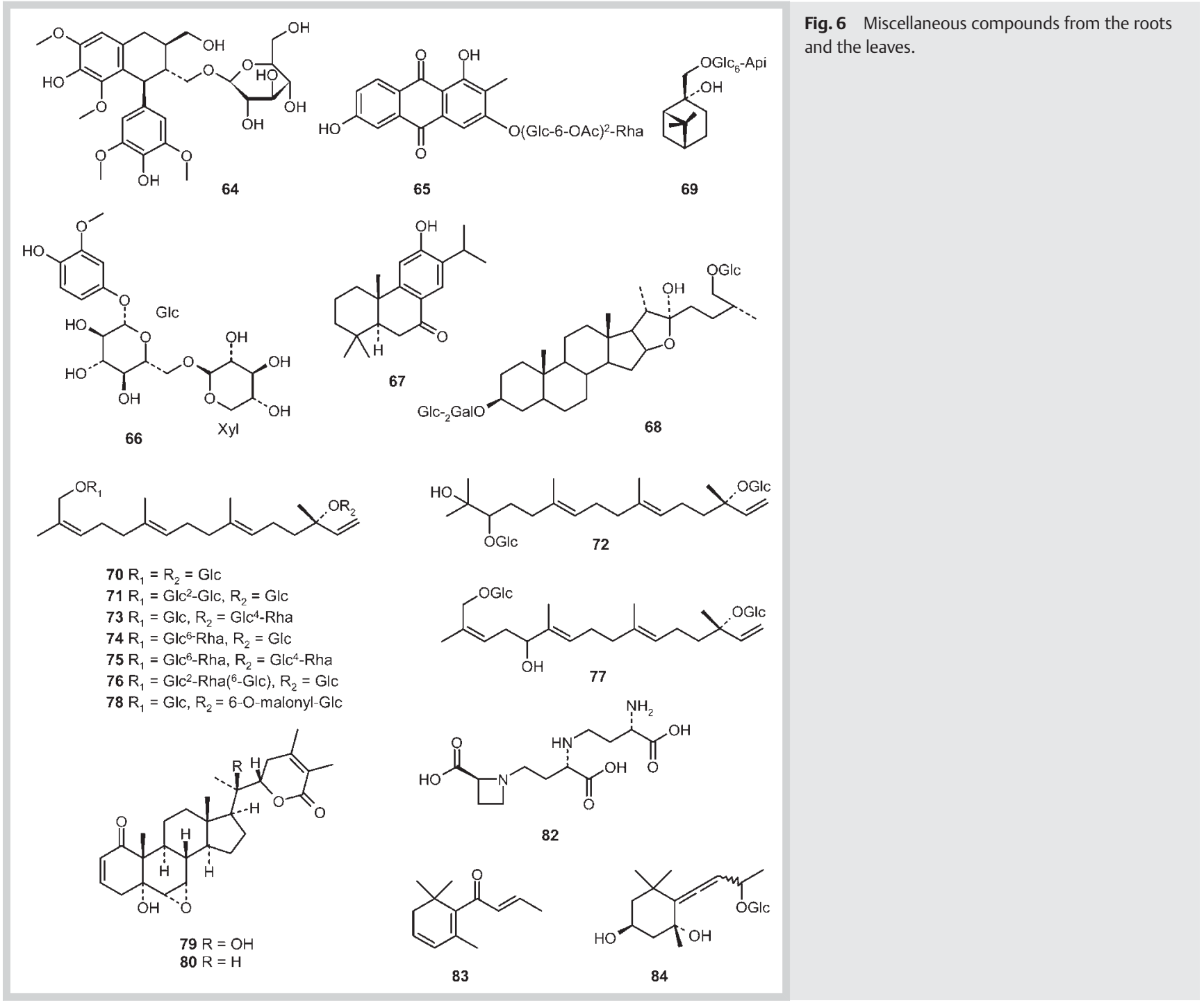

tate (1) [51]. Zeaxanthin dipalmitate reduced hepatic fibrosis induced by bile duct ligation/scission in rats at a dose of $25 \mathrm{mg} / \mathrm{kg}$ per os. The antifibrotic activity appears mediated, at least in part, by the antioxidative activity [122]. The two cerebrosides 25 and 26 were identified as active components in the EtOAc-soluble fraction after bioactivity-guided isolation [53]. These compounds showed protective effects on rat hepatocytes exposed to $\mathrm{CCl}_{4}$ [123] or galactosamine [124]. Some further compounds isolated from the fruit displayed hepatoprotective activity. Thus, the three pyrrole derivatives 27-29 showed protective effects comparable to silybin on $\mathrm{CCl}_{4}$-induced toxicity in rat hepatocytes [54]. Aqueous extracts demonstrated also protective effects in vivo against $\mathrm{CCl}_{4}$-induced liver toxicity as well as anti-inflammatory activity against carragenan induced rat paw edema [125]. However, it must be critically noted that in this study similar potencies were observed for the different plant parts which appears somewhat peculiar in view of their rather different chemical compositions. Moreover the data do not show clear dose/response effects. More recently, the hepatoprotective effect of the aqueous extract of the fruit administered orally was confirmed in rats intoxicated with $\mathrm{CCl}_{4}$. The underlying mechanism appears to involve antioxidative properties and a decrease of the expression of CYP2E1 [126].

\section{Root bark}

Investigations of the roots have focused on L.chinense. Several publications refer to a series of pharmacological activities including hypotensive, hypoglycemic, and antipyretic activities in animal models [69]. However the original data are for a large part not accessible and the mode of administration, as well as the exact Lycium species are unclear. Some data are available which support the use of the drug for hypertension. Thus, a methanol extract of the root has been shown to produce hypotension in rats at a dose of $0.5 \mathrm{~g} / \mathrm{kg}$ i.v. The spermine alkaloid kukoamine $\mathrm{A}$ (45) has been identified as the hypotensive principle [69]. The inhibitory activity of the peptides lyciumins A (34) and B (35), isolated from the root bark towards the angiotensin converting enzyme (ACE) and renin has been demonstrated in vitro [63]. Recently, the purification of a further ACE inhibitor (structure unknown) has been reported. According to the ESI-MS data (pseudomolecular ion at $m / z$ 862), the compound might be a further peptide of lyciunamin-type. Unfortunately, the part of the plant from which the compound has been purified is not indicated in the publication [127].

In addition to hypotensive properties, a few miscellaneous activities have been reported for the root bark: an EtOAc soluble fraction and the phenolic amides 41-44 isolated thereof exhibited 
antifungal properties [68]. Three of them (41-43) were also shown to possess superoxide scavenging properties [67]. As already mentioned, aqueous extracts demonstrated protective effects in vivo against $\mathrm{CCl}_{4}$-induced liver toxicity as well as anti-inflammatory activity against carragenan induced rat paw edema [125]. Finally, very weak inhibition against MAO-A ( $\mathrm{IC}_{50}$ $0.44 \mathrm{mg} / \mathrm{mL}$ ) and $\mathrm{B}\left(\mathrm{IC}_{50} 0.4 \mathrm{mg} / \mathrm{mL}\right)$ has been reported for a $50 \%$ aqueous methanol extract in the course of a general screening [128].

\section{Clinical Studies}

$\nabla$

Studies demonstrating the clinical efficacy of cortex Lycii against hypertension and diabetes are cited in some books on TCM drugs $[13,14]$. However, the original clinical data have only been published in national journals which are not accessible.

While there is some more information with regard to the clinical effects of the fruit, reliable data are essentially lacking. Investigations were mainly performed in China and have focused on agerelated conditions. Most studies were small-sized and not adequately controlled. Moreover, most literature is only available in abstract form since original data from Chinese publications are difficult to access. In most cases it is not clear whether L. barbarum or L.chinense has been used in these studies. In a representative study with 42 elderly participants, consumption of $50 \mathrm{mg}$ of wolfberry extract twice a day over two months decreased dizziness, fatigue, chest distress, sleep problems, and anorexia [129] (cited in [10]). However, significance was not statistically assessed in the study. In another study, ingestion of $50 \mathrm{~g} / \mathrm{d}$ of Goji berries in 25 elderly people for 10 days increased SOD and hemoglobin and decreased blood lipids significantly [130] (cited in [10]). Recently, in a first double-blind study performed outside China, the general effects of GoChi ${ }^{\mathrm{TM}}$, a commercial Goji juice, were investigated in young healthy adults. Various parameters were assessed by a questionnaire. Blood pressure and body weight were also monitored. The study concluded that consumption of GoChi ${ }^{\mathrm{TM}}$ for 14 days increased subjective feelings of general well-being and improved neurological performance as well as gastrointestinal function [131]. However, the small size of the study ( $\mathrm{N}=34)$ and the subjective assessment of most parameters must be critically pointed out. In a follow-up doubleblind study $(\mathrm{N}=30)$ sponsored by FreeLife International Company, the authors investigated the effect of GoChi ${ }^{\mathrm{TM}}$ on serum antioxidant markers in healthy Chinese adults aged 55-72 years. A significant increase of SOD and GSH-Px by 8.4 and $9.9 \%$ respectively and a concomitant decrease of MDA (malondialdehyde) by $8.7 \%$ were observed after 30 days [132]. These data are in agreement with previous observations [10] and may be indicative of possible beneficial effects in oxidative stress and age-related conditions.

In one of the most noted clinical studies on Goji, its effect as adjuvant in cancer therapy has been investigated. The study was conducted in China on 75 patients with various advanced cancers. Combination of IL-2/lymphokine-activated killer (LAK) therapy and L. barbarum polysaccharides afforded significantly higher response rates and longer remission rates than IL-2/LAK therapy alone [133]. Unfortunately, insufficient information is provided about the design of the study and the wolfberry supplements included in the diet to fully appraise the relevance of the data.
Clinical effects of Goji berries are generally attributed, at least for a large part, to LBP. However, data on bioavailability and pharmacokinetic behavior are still essentially lacking. In this context it should be noted that besides direct effects of LBP on pharmacological targets, indirect mechanisms have been suggested by which LBP could act in the gut as bioactive fibers or prebiotics $[132,134]$.

Finally, carotenoids from wolfberry have been investigated in the context of age-related eye diseases. While there are no data demonstrating the effect of the intake of Goji itself, there are many lines of evidence supporting the protective role of zeaxanthin. Thus, reduced incidence of cataract and macular degeneration has been linked to the consumption of leafy green vegetables, which constitute a rich source of zeaxanthin and lutein $[10,135$, 136]. A study with twelve volunteers who received free or esterified carotenoids extracted from Goji (L.barbarum) berries suspended in a yoghurt, confirmed the bioavailability of zeaxanthin. Moreover, the study indicated a strongly enhanced absorption of zeaxanthin diplamitate, the dominating carotenoid in Goji fruit, compared with the non-esterified form [137].

\section{Toxicology and Adverse Reactions}

Trace amounts of atropine detected in the fruit are of no toxicological relevance. In this context, the classification of Lycium barbarum in some books $[138,139]$ as a toxic plant is certainly unfounded. In a book on Chinese materia medica, the $\mathrm{LD}_{50}$ of a water extract of Goji berries is reported as $8.32 \mathrm{~g} / \mathrm{kg}$ by subcutaneous application in mice [140], which confirms the virtual absence of toxicity of the fruit. However, while there is no risk with cultivated plants, some caution is advised with samples of unknown origin, since confusion with morphologically similar Solanaceae fruits can not be excluded. Misidentification may be in fact at the origin of some contradictory data regarding the alkaloid content of Goji berries.

The root bark shows very low toxicity as well. Some data on acute toxicity have been reported in medicinal books but doses are unrealistically high and no references to the original studies are given. Thus, the $\mathrm{LD}_{50}$ of the decoction by intraperitoneal injection is reported to be $12.8 \mathrm{~g} / \mathrm{kg}$ in mice and $30 \mathrm{~g} / \mathrm{kg}$ in dogs. The $\mathrm{LD}_{50}$ by oral administration in dogs is $120 \mathrm{~g} / \mathrm{kg}[14,17]$. Vomiting appears in dogs receiving $120 \mathrm{~g} / \mathrm{kg}$ orally or $30 \mathrm{~g} / \mathrm{kg}$ intraperitoneally. In rabbits drowsiness was observed at doses of $80 \mathrm{~g} / \mathrm{kg}$ (orally) or $60 \mathrm{~g} / \mathrm{kg}$ (i.p.) [14]. In addition to these data of ill-defined origin, an increase in the weight of heart, liver and lungs was observed in the course of the assessment of subacute toxicity in rats with high doses ( 5 and $10 \mathrm{~g} / \mathrm{kg}$ ) orally over a test period of 14 days. A rise of blood urea nitrogen (BUN) and a decrease of creatinin were also noted as well as a raised count of white blood cells. However, there was no sign of any irreversible pathological damage or mortality in the rats. No modification of the locomotor activity, food consumption and water intake was observed [141]. In spite of the very long history of traditional use as food and herbal medicine, there are practically no reports of adverse effects due to Goji fruits. Only a few cases of allergic reactions including urticaria-like or papular rashes have been documented [12]. In Chinese medicinal books some caution is advised to pregnant women. Also it is recommended that patients suffering from diarrhea, fever, arthritis and strong inflammatory conditions should avoid the consumption of the fruit $[13,16,142]$. However, no rationale is given as to substantiate these recommendations. 
As to the root bark, adverse effects such as vertigo, palpitations, nausea, vomiting, and premature contractions have been reported, but only at high doses ( $50 \mathrm{~g}$ ), exceeding by far the normal dosage range of 5-15g [12]. Nevertheless, as for cooling agents (cold Yin agents) in general, the traditional Chinese medicine advises people suffering from Yang deficiency and/or weak stomach or spleen to consume the drug very sparingly [15]. The root is also contraindicated for patients with "exterior wind-cold" or "wind-heat conditions" and people who have "true cold but false heat" should use it with caution [13].

While the root bark and the fruit appear devoid of any acute toxicity, there are hints to potential drug interactions, as shown by two case reports documenting a possible interaction with warfarin. A 61-year-old Chinese woman stabilized on warfarin developed elevated international normalized ratio (INR) after drinking a tea of Goji berries over four days. The value returned to normal after discontinuing the tea [143]. Weak inhibition of CYP2C9 was detected in vitro. However, the very high dissociation constant $\left(K_{i}\right.$ of $3.4 \mathrm{mg} / \mathrm{mL}$ ) suggests that other mechanisms account for the drug interaction in vivo. In a further case which has been very recently reported, a 80-year-old Chinese woman on a chronic stable dose of warfarin experienced two episodes of an elevated INR after drinking an herbal tea containing L.barbarum [144]. Unfortunately, the report does not specify whether fruits or roots were taken and does not include data on the composition of the tea. The risk of drug interactions associated with Goji can not be definitively assessed, but caution is advised in particular for patients on medication with drugs with a narrow therapeutic index.

\section{Goji Products on the Novel Food Market \\ $\nabla$}

Goji is commonly designated as "Himalayan Goji berry" or "Tibetan Goji berry" on the global functional food market. The variety of commercialized products is considerable: besides juices, beers and wines, Goji is found in cookies, crispy bars, chocolate, muesli, sausages and soaps. Goji products have been marketed via Internet since 2002 and are also increasingly available in drugstores, "Reformhäuser", or organic food shops. Goji products are quite expensive with 30-50 dollars to be paid in average for a $1 \mathrm{~L}$ bottle on the Internet market. The recent commercial success of Goji in Western countries has been strongly pushed by a booklet of Dr. Earl Mindell published in 2003, entitled "Goji, The Himalayan Health Secret" [145]. Dr. Mindell is a controversial CanadianAmerican pharmacist and nutritionist who has written a series of books on food supplements and nutrition for the public. His theories on health and nutrition have met with deep scepticism in the scientific community. In the above-mentioned book, he extrapolates broad recommendations of uses for Goji juice, including cancer prevention, cardiovascular health, treatment of diabetes and obesity, from traditional practices and preliminary studies performed almost exclusively in China. In particular, he claims quasi-miraculous effects on life expectancy for Goji identified as "the Himalayan longevity fruit". Dr. Mindell and his statements about the "extraordinary value" of Goji are abundantly cited in advertisements for Goji products, in particular by his partner company FreeLife International which distributes Goji juice via multilevel marketing. The health benefits claimed by Dr. Mindell and to be found in the web publications of the Goji manufacturers have been individually and critically reviewed in a recent book on wolfberry [134]. The authors conclude that there are no scientific evidences and peer-reviewed proofs to validate any of the claims until now. One of the newest products is $\mathrm{GoChi}^{\mathrm{TM}}$, a juice claimed to contain over $30 \%$ more bioactive polysaccharides, which has been launched by FreeLife International in 2008. The name GoChi is a combination of go from Goji and the Chinese word chi meaning life energy. The advertising for this product draws on a recent clinical study supposed to have demonstrated the general effects of the product on health [131]. However, considering the highly subjective parameters, the small number of participants and the relatively short-term study, the relevance of this study is highly questionable.

Goji berries and Goji products are legally sold as food or food supplements in the USA and in Europe. However, these products cannot be promoted as drugs, and therapeutic claims are prohibited. In 2006 the FDA had to send warning letters to some Goji juice distributors about marketing claims which violated the Food Drug and Cosmetic Act [146,147]. In Europe, an evaluation procedure has been started by the UK Food Standards Agency in 2007 to establish whether Goji berries should receive the status of Novel Food, like Noni juice (Morinda citrifolia) in 2003 [148, 149]. After reviewing the data, the agency came to the conclusion that there were sufficient records of alimentary use of Goji in the UK before 1997 and that the fruit consequently does not fall under the Novel Food legislation [150]. As to the situation in the United States, Goji is not listed on the GRAS (generally regarded as safe) list of the FDA.

\section{Conclusions}

Goji has a long tradition of use in nutrition and medicine in East Asia. While the clinical efficacy is not yet established, various extracts, fractions and purified constituents were shown to exhibit interesting pharmacological properties in vitro and in vivo suggesting that they may be beneficial for the prevention and the treatment of age-related disorders. However, some of the activities were detected at very high concentrations only, and these studies should be considered with caution. Further investigations and in particular well-designed clinical trials with phytochemically well-characterized extracts are required before the potential of Goji as a medicinal plant can be definitively assessed. Concerning the numerous products found on the health food market, there are at the moment no scientific evidences to sustain the claims made for Goji juice as a "cure-all" or a miraculous drink for well-being and longevity. The fruit is devoid of toxicity, but caution is advised with regard to possible drug interactions as well as with products of unknown or dubious origin. The development of rigorous quality control procedures for Goji products is urgently needed.

\section{Acknowledgements \\ $\nabla$}

Mrs. Loredana Vasquez Briceno is gratefully acknowledged for bibliographic research.

\section{References}

1 Potterat 0 , Hamburger M. Goji juice: a novel miraculous cure for longevity and well being? A review of composition, pharmacology, health-related claims and benefits. Schweiz Zschr Ganzheitsmedizin 2008; 20: 399-405 
2 Zhang KYB, Leung HW, Yeung HW, Wong RNS. Differentiation of Lycium barbarum from its related Lycium species using random amplified polymorphic DNA. Planta Med 2001; 67: 379-381

3 Hänsel R, Keller K, Rimpler H, Schneider G. Hagers Handbuch der pharmazeutischen Praxis, Vol 5: Drogen E-O. Berlin, Heidelberg, New York: Springer Verlag; 1993

4 Sze SCW, Song JX, Wong RNS, Feng YB, Ng TB, Tong Y, Zhang KYB. Application of SCAR (sequence characterized amplified region) analysis to authenticate Lycium barbarum (wolfberry) and its adulterants. Biotechnol Appl Biochem 2008; 5: 15-21

5 Genaust $H$. Etymologisches Wörterbuch der botanischen Pflanzennamen, 3. Auflage. Basel: Birkhäuser Verlag; 1996

6 Qian J, Liu D, Huang A. The efficiency of flavonoids in polar extracts of Lycium chinense Mill. fruits as free radical scavenger. Food Chem 2004; 87: $283-288$

7 Stuart GA, Smith FP. Chinese Materia Medica. Shanghai: American Presbyterian Mission Press; 1911: 250

8 Bich DH, Tap N, Toan T, Hung T, Hien PV, Lo VN, Man PK, Dan NV, Nhu DT, Mai PD. Selected medicinal plants in Vietnam, volume 2. Hanoi: Science and Technology Publishing House; 1999

9 [no authors listed.] Pharmacopoeia of the People's Republic of China, English edition. Beijing: Chemical Industry Press; 2000

10 Burke DS, Smidt CR, Vuong LT. Momordica cochichinensis, Rosa roxburghii, wolfberry, and sea buckthorn - highly nutritional fruits supported by tradition and science. Curr Top Nutraceutical Res 2005; 3: 259-266

11 Zhufan X. Practical traditional Chinese medicine. Beijing: Foreign Language Press; 2000

12 Bensky D, Clavey S, Stöger E. Chinese herbal medicine, 3rd edition. Materia Medica. Seattle: Eastland Press, Inc.; 2004

13 Chen JK, Chen TT. Chinese medical herbology and pharmacology. City of Industry, CA: Art of Medicine Press, Inc.; 2004

14 Zhu YP. Chinese Materia Medica - chemistry, pharmacology and applications. Amsterdam: Harwood Academic Publishers; 1998

15 Reid DP. Chinesische Heilkunde. Stuttgart: Thieme Hippokrates Enke; 1995: 155, 224

16 Reid D. Handbuch der chinesischen Heilkräuter. München: Droemersche Verlagsanstalt Th Knaur Nachf; 1998

17 Huang KC. The pharmacognosy of Chinese herbs. Boca Raton: CRC Press; 1999: 333-334

18 Yin G, Dang Y. Optimization of extraction technology of the Lycium barbarum polysaccharides by Box-Behnken statistical design. Carbohydr Polym 2008; 74: 603-610

19 Peng X, Tian G. Structural characterization of the glycan part of glycoconjugate LbGp2 from Lycium barbarum L. Carbohydr Res 2001; 331: 96-99

20 Huang L, Lin Y, Tian G, Ji G. Isolation, purification and physicochemical properties of immunoactive glycoconjugates from fruit of Lycium barbarum L. Yaoxue Xuebao 1998; 33: 512-516

21 Huang L, Tian GY, Ji GZ. Structure elucidation of glycan of glycoconjugate LbGp3 isolated from the fruit of Lycium barbarum L. J Asian Nat Prod Res 1999; 1: 259-267

22 Peng X, Huang J, Qi C, Zhang YX, Tian GY. Studies on chemistry and immuno-modulating mechanism of a glycoconjugate from Lycium barbarum L. Chin J Chem 2001; 19: 1190-1197

23 Peng X, Qi C, Tian G, Zhang XX. Physico-chemical properties and bioactivities of a glycoconjugate LbGp5B from Lycium barbarum L. Chin J Chem 2001; 19: 842-846

24 Gan L, Zhang SH, Yang XL, Xu HB. Immunomodulation and antitumor activity by a polysaccharide-protein complex from Lycium barbarum. Int Immunopharmacol 2004; 1: 563-569

25 Zhao CJ, He YQ Li RZ, Cui GH. Chemistry and pharmacological activity of petidoglycan from Lycium barbarum. Chin Chem Lett 1996; 11: 1009_ 1010

26 Zhao C, Li R, He Y, Chui G. Studies on chemistry of Gouqi polysaccharides. Yie Daxue Xuebao 1997; 29: 231-232, 240 (CAN 129: 120129)

27 Chen Z, Tan BKH, Chan SH. Activation of T lymphocytes by polysaccharide-protein complex from Lycium barbarum L. Int Immunopharmacol 2008; 8: 1663-1671

28 Duan C, Qiao S, Wang N, Zhao Y, Qi C, Yao X. Studies on active polysaccharides from Lycium barbarum. Yaoxue Xuebao 2001; 36: 196-199

29 Wang CC, Chang SC, Chen BH. Chromatographic determination of polysaccharides in Lycium barbarum Linneaus. Food Chem 2009; 116: 595603

30 Li X, Zhou AG, Li XM. Inhibition of Lycium barbarum polysaccarides and Ganoderma lucidum polysaccharides against oxidative injury induced by $\gamma$-irradiation in rat liver mitochondria. Carbohydr Polym 2007; 69: $172-178$

31 Piao M, Murata Y, Zhu B, Shimoishi Y, Tada M. Changes in carotenoid content and its composition during maturation of Fructus lycii fruits. Jpn J Food Chem 2005; 12: 35-39 (CAN 144: 169735)

32 Weller $P$, Breithaupt DE. Identification and quantification of zeaxanthin esters in plants using liquid chromatography-mass spectrometry. J Agric Food Chem 2003; 51: 7044-7049

33 Peng Y, Ma C, Li Y, Leung KSY, Jiang ZH, Zhao Z. Quantification of zeaxanthin dipalmitate and total carotenoids in Lycium fruits (Fructus lycii). Plant Foods Hum Nutr 2005; 60: 161-164

34 Inbaraj BS, Lu H, Hung CF, Wu WB, Lin CL, Chen BH. Determination of carotenoids and their esters in fruits of Lycium barbarum Linnaeus by HPLC-DAD-APCI-MS. J Pharm Biomed Anal 2008; 47: 812-818

35 Molnar P, Pfander H, Olah P, Deli J, Toth G. Carotenoid composition of Lycium barbarum L. seeds of Chinese and Hungarian origin. Olaj, Szappan, Kozmetika 2003; 52: 50-55 (CAN 140: 108103)

36 Qi Z, Li S, Wu J, Qu R, Yang Y, Zhang, L, Yang X. Chemical constituents of Fructus lycii and Folium lycii - nutrients in Fructus lycii and Folium lycii. Zhongyao Tongbao (Beijing, China) 1986; 11: 169-171

37 Toyoda-Ono Y, Maeda M, Nakao M, Yoshimura M, Sugiura-Tomimori N, Fukami H. 2-O-( $\beta$-D-Glucopyranosyl)ascorbic acid, a novel ascorbic acid analogue isolated from Lycium fruit. J Agric Food Chem 2004; 52 : 2092-2096

38 Le K, Chiu F, $\mathrm{Ng} \mathrm{K}$. Identification and quantification of antioxidants in Fructus lycii. Food Chem 2007; 105: 353-363

39 Altintas A, Kosar M, Kirimer N, Baser KH, Demirci B. Composition of the essential oils of Lycium barbarum and Lycium ruthenicum fruits. Chem Nat Comp 2006; 41: 24-25

40 Gao Z, Ali Z, Khan IA. Glycerogalactolipids from the fruit of Lycium barbarum. Phytochemistry 2008; 69: 2856-2861

41 Chen S, Wang $Q$, Gong S, Wu J, Yu X, Lin S. Analysis of amino acid in Fructus lycii. Zhongguo Yaoke Daxue Xuebao 1991; 22: 53-55 (CAN 115: 15369)

42 Cao Y, Zhang X, Chu Q Fang Y, Ye J. Determination of taurine in Lycium barbarum L. and other foods by capillary electrophoresis with electrochemical detection. Electroanalysis 2003; 15: 898-902

43 Wang $Q$ Qiu Y, He SP, Chen YY. Chemical constituents of the fruit of $L y$ cium barbarum L. J Chin Pharm Sci 1988; 7: 218-220

44 Zou C, Zhao $Q$ Chen CX, He YN. New dopamine derivative from Lycium barbarum. Chin Chem Lett 1999; 10: 131-132

45 Hiserodt RD, Adedeji J, John TV, Dewis ML. Identification of monomenthyl succinate, monomenthyl glutarate, and dimenthyl glutarate in nature by high performance liquid chromatography-tandem mass spectrometry. J Agric Food Chem 2004; 52: 3536-3541

46 Harsh ML. Tropane alkaloids from Lycium barbarum Linn., in vivo and in vitro. Curr Sci 1989; 58: 817-818

47 Adams M, Wiedenmann M, Tittel G, Bauer R. HPLC-MS trace analysis of atropine in Lycium barbarum berries. Phytochem Anal 2006; 17: 279283

48 Qin X, Yamauchi R, Aizawa K, Inakuma T, Kato K. Isolation and characterization of arabinogalactan-protein from the fruit of Lycium chinense. Mill. J Appl Glycosci 2000; 47: 155-160

49 Qin X, Yamauchi R, Aizawa K, Inakuma T, Kato K. Structural features of arabinogalactan-proteins from the fruit of Lycium chinense Mill. Carbohydr Res 2001; 333: 79-85

50 Qin X, Lin H. Isolation and characteristics of araban isolated from fruit of Lycium chinense Mill. Shipin Kexue 2003; 24: 52-56

$51 \mathrm{Kim} \mathrm{SY,} \mathrm{Kim} \mathrm{HP,} \mathrm{Huh} \mathrm{H,} \mathrm{Kim} \mathrm{C.} \mathrm{Antihepatotoxic} \mathrm{zeaxanthins} \mathrm{from} \mathrm{the}$ fruit of Lycium chinense. Arch Pharm Res 1997; 20: 529-532

52 Noculak-Palczewska A, Matkowski A, Gasiorowski K, Tabaka H, Oszmianski J, Lamer-Zarawska E. Chemical characterisation of methanolic-water extracts from the fruit of acclimated Lycium chinense Mill. Herba Pol 2004: 50: 47-53

53 Kim SY, Choi YH, Huh H, Kim J, Kim YC, Lee HS. New antihepatotoxic cerebroside from Lycium chinense fruits. J Nat Prod 1997; 60: 274-276

54 Chin YW, Lim SW, Kim SH, Shin DY, Suh YG, Kim YB, Kim YC, Kim J. Hepatoprotective pyrrole derivatives of Lycium chinense fruits. Bioorg Med Chem Lett 2003; 13: 79-81

55 Itoh T, Tamura T, Matsumoto T. Triterpene alcohols in the seeds of Solanaceae. Phytochemistry 1977; 16: 1723-1726

56 Itoh T, Ishi T, Tamura T, Matsumoto T. Four new and other $4 \alpha$-methylsterols in the seeds of Solanaceae. Phytochemistry 1978; 17: 971-977

57 Itoh T, Tamura T, Matsumoto T. 4-desmethylsterols in the seeds of Solanaceae. Steroids 1977; 30: 425-433 
58 Jung K, Chin YW, Kim YC, Kim J. Potentially hepatoprotective glycolipid constituents of Lycium chinense fruits. Arch Pharm Res 2005; 28: 1381 1385

59 Sannai A, Fujimori T, Kato K. Neutral volatile components of "kukoshi” (Lycium chinense M.). Agric Biol Chem 1983; 47: 2397-2399

60 Sannai A, Fujimori T, Kato K. Isolation of (-)-1,2-dehydro- $\alpha$-cyperone and solavetivone from Lycium chinense. Phytochemistry 1982; 21: 2986-2987

61 Lee GH, Shin Y, Oh MJ. Aroma-active components of Lycii fructus (kukija). J Food Sci 2008; 73: C500-C505

62 Yahara S, Shigeyama C, Ura T, Wakamatsu K, Yasuhara T, Nohara T. Cyclic peptides, acyclic diterpene glycosides and other compounds from Lycium chinense Mill. Chem Pharm Bull 1993; 41: 703-709

63 Yahara S, Shigeyama C, Nohara T. Structures of anti-ACE and -renin peptides from Lycii radicis cortex. Tetrahedron Lett 1989; 30: 60416042

64 Morita H, Yoshida N, Takeya K, Itokawa H, Shirota O. Configurational and conformational analyses of a cyclic octapeptide, lyciumin A, from Lycium chinense Mill. Tetrahedron 1996; 52: 2795-2802

65 Morota T, Sasaki H, Chin M, Sato T, Katayama N, Fukuyama K, Mitsuhashi $H$. Studies on the crude drug containing the angiotensin I-converting enzyme inhibitors (I). The active principles of Lycium chinense Miller. Shoyakugaku Zasshi 1987; 41: 169-173 (CAN 108: 192630)

66 Noguchi M, Mochida K, Shingu T, Kozura M, Fujitani K. Über die Bestandteile der chinesischen Droge „Ti-ku'pi“. I. Isolierung und Konstitution von Lyciumamid, einem neuen Dipeptid. Chem Pharm Bull 1984; 32: 3584-3587

67 Han SH, Lee HH, Lee IS, Moo YH, Woo ER. A new phenolic amide from Lycium chinense Miller. Arch Pharm Res 2002; 25; 433

68 Lee DG, Park Y, Kim MR, Jung HJ, Seu YB, Hahm KS, Woo ER. Antifungal effects of phenolic amides isolated from the root bark of Lycium chinense. Biotechnol Lett 2004; 26: 1125-1130

69 Funayama S, Yoshida K, Konno C, Hikino H. Structure of kukoamine A, a hypotensive principle of Lycium chinense root barks. Tetrahedron Lett 1980; 21: 1355-1356

70 Funayama S, Zhang GR, Nozoe S. Kukoamine B, a spermine alkaloid from Lycium chinense. Phytochemistry 1995; 38: 1529-1531

71 Asano N, Kato A, Miyauchi M, Kizu H, Tomimori T, Matsui K, Nash RJ, Molyneux RJ. Specific $\alpha$-galactosidase inhibitors, N-methylcalystegines. Structure/activity relationships of calystegines from Lycium chinense. Eur J Biochem 1997; 248: 296-303

72 Chu Q, Fu L, Lin M, Ye J. Study on bioactive ingredients in Cortex lycii by capillary zone electrophoresis with amperometric detector. Fenxi Huaxue 2005; 33: 1611-1614

73 Wei X, Liang J. Chemical studies on the root bark of Lycium chinense. Zhongcaoyao 2003; 34: 580-581 (CAN 141: 346494)

74 Wei X, Liang J. Chemical study on the root bark of Lycium chinense Mill. Zhongguo Yaoke Daxue Xueba 2002; 33: 271-273 (CAN 141: 137021)

75 Lee, DG, Jung HJ, Woo ER. Antimicrobial property of (+)-lyoniresinol$3 \alpha-O-\beta-D$-glucopyranoside isolated from the root bark of Lycium chinense Miller against human pathogenic microorganisms. Arch Pharm Res 2005; 28: 1031-1036

76 Li Y, Li P, Tu P, Chang H. Identification of chemical constituents of Lycium chinense. Zhongcaoyao 2004; 35: 1100-1101

77 Noguchi M, Mochida K, Shingu T, Fujitani K, Kozuka M. Sugiol and $5 \alpha-$ stigmastane-3,6-dione from the Chinese drug “Ti-ku-p'i” (Lycii Radicis Cortex). J Nat Prod 1985; 48: 342-343

78 Zhou X, Xu G, Wang Q. Studies on the chemical constituents in the roots of Lycium chinense mill. Zhongguo Zhongyao Zazhi 1996; 21: 675-676 (CAN 126: 255338)

79 Mizobuchi K, Inoue Y, Kiuch T, Higashi J. Constituents of box thorn. II. Chemical components of the root bark of box thorn. Shoyakugaku Zasshi 1963; 17: 16-18 (CAN 62: 16825)

80 Drost-Karbowska K, Hajdrych-Szaufer M, Kowalewski Z. Search for alkaloid-type bases in Lycium halimifolium. Acta Pol Pharm 1984; 41: 127129 (CAN 101: 167206)

81 Terauchi M, Kanamori H, Nobuso M, Yahara S, Yamasaki K. New acyclic diterpene glycosides, lyciumosides IV-IX from Lycium chinense Mill. Nat Med 1998; 52: 167-171

82 Jassbi AR, Zamanizadehnajari S, Kessler D, Baldwin IT. A new acyclic diterpene glycoside from Nicotiana attenuata with a mild deterrent effect on feeding Manduca sexta larvae. Z Naturforsch 2006; 61 [b]: 1138-1142

83 Haensel R, Huang JT, Rosenberg D. Zwei Withanolide aus Lycium chinese. Arch Pharm 1975; 308: 653-654
84 Imai S, Murata T, Fujioka S, Goto M. Isolation of $\beta$-sitosterol $\beta$-D-glucoside from the leaves of Lycium chinense. Yakugaku Zhassi 1963; 83: 1092 (CAN 60: 52965)

85 Zou Y. Flavones in leaves of Lycium chinense. Fenxi Ceshi Xuebao 2002; 21: 76-78 (CAN 137: 75890)

86 Terauchi M, Kanamori H, Nobuse M, Yahara S, Nohara T. Detection and determination of antioxidative components in Lycium chinense. Nat Med 1997; 51: 387-391

87 Aubert C, Kapetanidis I. New flavonoids from Lycium chinense. Planta Med 1989; 55: 612

88 Haensel R, Huang JT. Lycium chinense, III. Isolierung von Scopoletin und Vanillinsäure. Arch Pharm 1977; 310: 38-40

89 Noma $M$, Noguchi $M$. Occurence of nicotianamine in higher plants. Phytochemistry 1976; 15: 1701-1702

90 Yoshimura Y, Take T, Otsuka H, Daigaku N, Niagata J. Taste substances in foods. XIV. Taste substances in the leaves of box thorn (Lycium chinense). Kaseigaku Zasshi 1969; 20: 481-484 (CAN 72: 109981)

91 Kim SY, Lee KH, Chang KS, Bock JY, Jung MY. Taste and flavor compounds in box thorn (Lycium chinense Miller) leaves. Food Chem 1997; 58: 297-303

92 Sannai A, Fujimori T, Wegaki R, Akaki T. Isolation of 3-hydroxy-7,8-dehydro- $\beta$-ionone from Lycium chinense M. Agric Biol Chem 1984; 48 : $1629-1630$

93 Christen P, Kapetanidis I. Flavonoids from Lycium halimifolium. Planta Med 1987; 53: 571-572

94 Näf $R$, Velluz A, Thommen $W$. Isolation of a glucosidic precursor of damascenone from Lycium halimifolium Mil. Tetrahedron Lett 1990; 45: 6521-6522

95 Zhao Q Li C, Zhou D. Chemical constituents of Gouqi (Lycium barbarum) leaf. Zhongcaoyao 1987; 18: 104, 133 (CAN 107: 93549)

96 Qi Z, Li S, Wu J, Qu R, Yang Y, Zhang L, Yang X. Chemical constituents of Fructus lycii and Folium lycii. (I). Nutrients in Fructus lycii and Folium lycii. Zhongyao Tongbao 1986; 11: 163, 169-171 (CAN 105: 3596)

97 Harsh ML, Nag TN. Diosgenin and phytosterols from Lycium barbarum Linn. Curr Sci 1981; 50: 235

98 Chang RCC, So KF. Use of anti-aging herbal medicine, Lycium barbarum, against aging-associated diseases. What do we know so far? Cell Mol Neurobiol 2008; 28: 643-652

$99 \mathrm{Li} \mathrm{XM}, \mathrm{Li} \mathrm{XL}$, Zhou AG. Evaluation of antioxidant activity of the polysaccharides extracted from Lycium barbarum fruits in vitro. Eur Polymer 2007; 43: 488-497

$100 \mathrm{Li}$ XL, Zhou AG. Evaluation of the antioxidant effects of polysaccharides extracted from Lycium barbarum. Med Chem Res 2007; 15: 471-482

101 Ren B, Ma Y, Sheng Y, Gao B. Protective action of Lycium barbarum L and betaine on lipid peroxidation of RBC membrane induced by hydrogen peroxide. Zhongguo Zhongyao Zazhi 1995; 20: 303-304 (CAN 124: 21718)

102 Luo Q Li Z, Huang X, Yan J, Zhang S, Cai Y. Lycium barbarum polysaccharides: protective effects against heat-induced damage of rat testes and $\mathrm{H}_{2} \mathrm{O}_{2}$-induced DNA damage in mouse testicular cells and beneficial effect on sexual behavior and reproductive function of hemicastrated rats. Life Sci 2006; 79: 613-621

103 Ma L, Chen Q Yang W, Xi S, Wan X, Tang X, Yu Y, KangJ. Effect of Lycium barbarum polysaccharide against atherosclerosis in rabbits. Zhengzhou Daxue Xuebao, Yixueban 2005; 40: 328-330 (CAN 144: 324440)

104 Ming M, Guanhua L, Zhanhai Y, Guang C, Xuan Z. Effect of the Lycium barbarum polysaccharides administration on blood lipid metabolism and oxidative stress of mice fed high-fat diet in vivo. Food Chem 2009; 113: $872-877$

$105 \mathrm{Wu}$ H, Guo H, Zhao R. Effect of Lycium barbarum polysaccharide on the improvement of antioxidant ability and DNA damage in NIDDM rats. Yakugaku Zasshi 2006; 126: 365-371

106 Li XM. Protective effect of Lycium barbarum polysaccharides on streptozotocin-induced oxidative stress in rats. Int J Biol Macromol 2007; 40: 461-465

107 Zhao $R$, Li Q Xiao B. Effect of Lycium barbarum polysaccharide on the improvement of insulin resistance in NIDDM rats. Yakugaku Zasshi 2005; 125: 981-988

108 Luo Q Cai Y, Yan J, Sun M, Corke H. Hypoglycemic and hypolipidemic effects and antioxidant activity of fruit extracts from Lycium barbarum. Life Sci 2004; 76: 137-149

109 Du G, Liu L, Fang J. Experimental study of the enhancement of murine splenic lymphocyte proliferation by Lycium barbarum glycopeptide. J Huazhong Univ Sci Technol 2004; 24: 518-520 
110 Chen Z, Lu J, Srinivasan N, Tan BKH, Chan SH. Polysaccharide-protein complex from Lycium barbarum L. is a novel stimulus of dendritic cell immunogenicity. J Immunol 2009; 182: 3503-3506

111 Gan L, Zhang SH, Liu Q Xu HB. A polysaccharide-protein complex from Lycium barbarum upregulates cytokine expression in human peripheral blood mononuclear cells. Eur J Pharmacol 2003; 471: 217-222

112 Gan L, Zhang SH, Yang XL, Xu HB. Immunomodulation and antitumor activity by a polysaccharide-protein complex from Lycium barbarum. Int J Immunopharmacol 2004; 4: 563-569

113 Zhang M, Chen H, Huang J, Li Z, Zhu C, Zhang S. Effect of Lycium barbarum polysaccharide on human hepatoma QGY7703 cells: Inhibition of proliferation and induction of apoptosis. Life Sci 2005; 76: 2115-2124

114 Chao JCJ, Chiang SW, Wang CC, Tsai YH, Wu MS. Hot water-extracted Lycium barbarum and Rehmannia glutinosa inhibit proliferation and induce apoptosis of hepatocellular carcinoma cells. World J Gastroenterol 2006; 12: 4478-4484

115 Liu X, Sun J, Li H, Zhang L, Qian B. Extraction and isolation of active component in fruit of Lycium barbarum for inhibiting PC3 cell proliferation in vitro. Zhongguo Zhongyao Zazhi 2000; 25: 481-483 (CAN 134: 263473)

116 Li G, Sepkovic W, Bradlow HL, Telang NT, Wong GYC. Lycium barbarum inhibits growth of estrogen receptor positive human breast cancer cells by favorably altering estradiol metabolism. Nutr Cancer 2009; 61: 408-414

117 Gong H, Shen P, Jin L, Xing C, Tang F. Therapeutic effects of Lycium barbarum polysaccharide (LBP) on irradiation or chemotherapy-induced myelosuppressive mice. Cancer Biother Radiopharm 2005; 20: 155162

118 Yu MS, Leung SKY, Lai SW, Che CM, Zee SY, So KF, Yuen WH, Chang RCC. Neuroprotective effects of anti-aging oriental medicine Lycium barbarum against beta-amyloid peptide neurotoxicity. Exp Gerontol 2005; 40: 716-727

119 Yu MS, Ho YS, So KF, Yuen WH, Chang CC. Cytoprotective effects of $L y$ cium barbarum against reducing stress on endoplasmic reticulum. Int J Mol Med 2006; 17: 1157-1161

120 Yu MS, Lai Cora SW, Ho YS, Zee SY, So KF, Yuen WH, Chang RCC. Characterization of the effects of anti-aging medicine Fructus Lycii on beta amyloid peptide neurotoxicity. Int J Mol Med 2007; 20: 261-268

121 Chan HC, Chang RCC, Ip AKC, Chiu K, Yuen WH, Zee SY, So KF. Neuroprotective effects of Lycium barbarum Lynn on protecting retinal ganglion cells in an ocular hypertension model of glaucoma. Exp Neurol 2007; 203: 269-273

122 Kim HP, Lee EJ, Kim YC, Kim J, Kim HK, Park JH, Kim SY, Kim YC. Zeaxanthin dipalmitate from Lycium chinense fruit reduces experimentally induced hepatic fibrosis in rats. Biol Pharm Bull 2002; 25: 390392

123 Kim SY, Lee EJ, Kim HP, Kim YC, Moon A, Kim YC. A novel cerebroside from Lycii fructus preserves the hepatic glutathione system in primary cultures of rat hepatocytes. Biol Pharm Bull 1999; 22: 873-875

124 Kim SY, Lee EJ, Kim HP, Lee HS, Kim YC. LCC, a cerebroside from Lycium chinense, protects primary cultured rat hepatocytes exposed to galactosamine. Phytother Res 2000; 14: 448-451

125 Lin CC, Chuang SC, Lin JM, Yang JJ. Evaluation of the anti-inflammatory hepatoprotective and antioxidant activities of Lycium chinense from Taiwan. Phytomedicine 1997; 4: 213-220

126 Ha KT, Yoon SJ, Choi DY, Kim DW, Kim JK, Kim CH. Protective effect of Lycium chinense fruit on carbon tetrachloride-induced hepatotoxicity. J Ethnopharmacol 2005; 96: 529-535

127 Lee S, Song KB. Isolation of an angiotensin converting enzyme inhibitory substance from Lycium chinense Miller. J Food Sci Nutr 2004; 9: 95-97

128 Lin RD, Hou WC, Yen KY, Lee MH. Inhibition of monoamine oxidase B (MAO-B) by Chinese herbal medicines. Phytomedicine 2003; 20: 650656

129 Li DY, Yuan XL, Xia HF, Ma L, Guo ZY, Shen YY, Rong QZ. Preliminary clinical observations for effects of Ning Xia wolfberry extract on old peoples. Chin Tradit Herb Drugs 1989; 20: 26-28

130 Li W, Dai SZ, Ma W, Gao L. Effects of oral administration of wolfberry on blood superoxide dismutase (SOD), haemoglobin ( $\mathrm{Hb}$ ) and lipid peroxide (LPO) levels in old people. Chin Tradit Herb Drugs 1991; 22: 251,268

131 Amagase H, Nance DM. A randomized, double-blind, placebo-controlled, clinical study of the general effects of a standardized Lycium barbarum (Goji) juice, GoChi' ${ }^{\mathrm{TM}}$. J Altern Compl Med 2008; 14: 403412

132 Amagase H, Sun B, Borek C. Lycium barbarum (goji) juice improves in vivo antioxidant biomarkers in serum of healthy adults. Nutr Res 2009; 29: 19-25

133 Cao GW, Yang WG, Du P. Observation of the effects of LAK/IL-2 therapy combining with Lycium barbarum polysaccharides in the treatment of 75 cancer patients. Zhonghua Zhong Liu Za Zhi (Chin J Oncol) 1994; 16: 428-431

134 Gross PM, Zhang X, Zhang R. Wolfberry: nature's bounty of nutrition \& health. Lake Dalla: Booksurge Publishing; 2003

135 Brown L, Rimm EB, Seddon JM, Giovannucci EL, Chasan-Taber L, Spiegelman D, Willett WC, Hankinson SE. A prospective study of carotenoid intake and risk of cataract extraction in US men. Am J Clin Nutr 1999; 70: 517-524

136 Seddon JM, Ajani UA, Sperduto RD, Hiller R, Blair N, Burton TC, Farber MD, Gragoudas ES, Haller J, Miller DT, Yanmuzi LA, Willett W. Dietary carotenoids, vitamins A, C, and E, and advanced age-related macular degeneration. J Am Med Assoc 1994; 272: 1413-1420

137 Breithaupt DE, Weller P, Wolters M, Hahn A. Comparison of plasma responses in human subjects after the ingestion of 3R,3R'-zeaxanthin dipalmitate from wolfberry (Lycium barbarum) and non-esterified 3R,3R'-zeaxanthin using chiral high-performance liquid chromatography. Brit J Nutr 2004; 91: 707-713

138 Schönfelder I, Schönfelder P. Der neue Kosmos Heilpflanzenführer. Stuttgart: Kosmos-Verlag; 2001

139 Roth L, Daunderer M, Kormann K. Giftpflanzen - Pflanzengifte, 3. Auflage. Landsberg, München: Ecomed Verlagsgesellschaft; 1988

140 Chang HM, But PPH, Yao SC, Wang L, Yeung SCS. Pharmacology and applications of Chinese Materia Medica, volume 2. New Jersey, London, Singapore, Hong Kong: World Scientific; 2001

141 Yang HS, Chen CF. Subacute toxicity of 15 commonly used Chinese drugs (II). J Food Drug Anal 1997; 5: 355-380

142 Tierra M. Westliche Heilkräuter in TCM und Ayurveda. München, Jena: Urban \& Fischer Verlag; 2001

143 Lam AY, Elmer GW, Mohutsky MA. Possible interaction between warfarin and Lycium barbarum L. Ann Pharmacother 2001; 35: 11991201

144 Leung H, Hung A, Hui ACF, Chan TYK. Warfarin overdose due to the possible effects of Lycium barbarum L. Food Chem Toxicol 2008; 46 : 1860-1862

145 Mindell E, Handel R. Goji. The Himalayan health secret. Dallas: Momentum Media; 2003

146 Food and Drug Administration. Letter of notice Ref. No. CL-06HFS-810-214. May 8 2006. Available at http://www.fda.gov/downloads/Drugs/GuidanceComplianceRegulatoryInformation/EnforcementActivitiesbyFDA/CyberLetters/ucm056372.pdf. Accessed August 7,2009

147 Food and Drug Administration. Letter of notice Ref. No. CL-06HFS-810-226. August 7 2006. Available at http://www.fda.gov/downloads/Drugs/GuidanceComplianceRegulatoryInformation/EnforcementActivitiesbyFDA/CyberLetters/ucm056356.pdf. Accessed August 7, 2009

148 Potterat 0 , Hamburger M. Morinda citrifolia (Noni) fruit: phytochemistry, pharmacology, safety. Planta Med 2007; 73: 191-199

149 European Commission. Commission decision of 5 June 2003 authorising the placing on the market of "noni juice“ (juice of the fruit of Morinda citrifolia L.) as a novel food ingredient under Regulation (EC) Nr.258/97 of the European Parliament and of the Council. Official Journal of the European Union 2003: L 144/12, 12.6.2003

150 Food Standards Agency. Responses on Goji berries reviewed. 15 June 2007. Available at http://www.food.gov.uk/multimedia/pdfs/gojiberriesrep.pdf. Accessed August 7, 2009 